\title{
Utilisation de la biomasse des bactéries de la fermentation lactique pour la fabrication des fromages
}

\author{
par \\ J. RYMASZEWSKI, S. POZNANSKI \\ et Cz. MAGINSKA \\ Institut du Génie et de la Biotechnologie Alimentaire \\ Université d'Agriculture, Olsztyn (Pologne)
}

Le procédé traditionnel de la fabrication des levains ne permet pas toujours d'obtenir l'activité et le rendement maximum des germes bactériens. L'activité insuffisante des levains peut être causée, entre autres, par des propriétés du lait, la dégénérescence des germes, ou bien la présence des bactériophages et des antibiotiques. L'activité réduite du levain exerce une influence décisive sur le cours de la fabrication et l'affinage du fromage, et par suite, sur sa qualité. C'est pourquoi on cherche aujourd'hui d'autres solutions pour la production et la conservation des levains.

Il paraît que la biomasse des bactéries lactiques peut satisfaire des exigences que l'on pose aux meilleurs levains de fromagerie.

Des études intéressantes sur la culture de la biomasse des bactéries lactiques ont été faites par Bergère [2-4], Bergère et Hermier [3]. Ils ont obtenu un rendement élevé $\left(2-3-10^{10}\right.$ germes $\left./ \mathrm{ml}\right)$, en bactéries qui ne montraient aucune réduction d'activité et de viabilité pendant le stockage à l'état congelé.

La méthode de culture des bactéries lactiques en lait dégraissé et de leur conservation par condensation et séchage a été décrit par Stadhouders et al. [15].

Vallès et Mocquot [18] ont mis au point la méthode pour cultiver la biomasse des bactéries thermophiles en lactosérum enrichi.

Rousseau et al. [16] ont appliqué la biomasse ainsi préparée pour compléter la microflore dans la fabrication des fromages de Gruyère de Comté. Ils rapportent que l'addition de la biomasse au lait cru, outre le levain normal, exerce une influence favorable sur la cinétique des changements du $\mathrm{pH}$ au cours de la fabrication, ainsi que sur la structure et la consistance des fromages. 
C'est pourquoi nous avons essayé d'utiliser la biomasse des bactéries lactiques, au lieu du levain, pour la fabrication des fromages, en tâchant en même temps d'étudier le procédé technologique et le degré de dégradation de la paracaséine, en comparaison avec des fromages fabriqués à l'aide de levain.

\section{EXPERIMENTATION}

Le milieu de culture des bactéries était préparé d'après Vallès et Mocquot [18], avec une certaine modification, de la manière suivante : $50 \mathrm{~g}$ de lait écrémé en poudre était dilué dans 11 de lactosérum de présure, et le tout était stérilisé puis additionné de 0,6 g de papaïne à $42-45^{\circ} \mathrm{C}(1: 400)$ et incubé à la même température pendant $24 \mathrm{~h}$.

Après l'incubation, le tout était pasteurisé pendant $15 \mathrm{mn}$, clarifié et, après addition de l'extrait de levure Difco $5 \mathrm{~g} / 1$ et $\mathrm{MnSO}_{4}$ $2 \mathrm{H}_{2} \mathrm{O}-0,12 \mathrm{~g} / 1$, stérilisé de nouveau.

Des bactéries de la fermentation lactique : Str. lactis $\mathrm{T}_{1}$, Str. diacetilactis 157 et Str. cremoris 319 étaient obtenues par la méthode de la culture stationnaire, le $\mathrm{pH}$ étant ajusté entre 5,9 et 6,5 en ajoutant $5 \mathrm{~N} \mathrm{NaOH}$ stérilisé avec l'agitation continuelle. Str. lactis et Str. diacetilactis étaient cultivés à la température de $25^{\circ} \mathrm{C}$, et Str. cremoris à celle de $30^{\circ} \mathrm{C}$. Après la centrifugation, le précipitat des germes était dilué en $100 \mathrm{ml}$ de lait reconstitué et congelé à $-25^{\circ} \mathrm{C}$.

En même temps, les mêmes bactéries étaient cultivées d'une manière analogue, avec la seule différence qu'au lieu d'être centrifugées, on refroidissait le tout jusqu'à $5^{\circ} \mathrm{C}$ et on le conservait dans des thermos jusqu'au moment d'usage (environ $7-8 \mathrm{~h}$ ).

Des études sur l'application de la biomasse ont été faites au cours de la fabrication de fromages Edam. Trois séries de fabrication (lots) étaient préparées. Dans la première série, le levain de fromagerie usuel était employé (lot $K_{1}$ ), la biomasse, centrifugée et congelée, étant ajoutée, à la quantité de 0,2 p. 100 par rapport au lait, à une partie de la pâte du fromage, après la séparation du lactosérum, juste avant le pressage préliminaire (lot $D_{1}$ ). Dans la série II, la biomasse refroidie était employée, en l'ajoutant au lait, à la quantité de 2 p. 100 , juste avant l'emprésurage (lot $D_{2}$ ). En même temps, des fromages témoins étaient fabriqués du même lait, en usant du levain de mêmes souches (lot $\mathrm{K}_{2}$ ), qui étaient cultivées séparément et mélangées en proportion $1: 1: 1$, juste avant de les ajouter au lait. La biomasse était mélangée en même proportion.

Dans la série III, la biomasse centrifugée et congelée à la quantité de 0,15 p. 100 (lot $\mathrm{D}_{3}$ ) et la biomasse refroidie sans centrifugation 
(lot $\mathrm{D}_{4}$ ) à la quantité de 1,5 p. 100 étaient employées. En même temps, on fabriquait des fromages témoins, en employant des levains de mêmes souches (lot $K_{s}$ ), qu'on avait cultivées séparément, pour les mélanger, avant d'introduire au lait de fromageries, aux proportions suivantes : Str. lactis 2 parties, Str. cremoris 1 partie et Str. diacetilactis 1 partie. La biomasse était mélangée à la même proportion.

Dans le fromage récemment moulé, après pressage, $24 \mathrm{~h}$ après la fabrication et la salaison, les déterminations suivantes étaient effectuées : $\mathrm{pH}$, pouvoir tampon, par la méthode Czulak et al. [6] et lactose, d'après Swartling et Mattson [16]. Après 6 et 12 semaines d'affinage, l'examen organoleptique était fait, et on déterminait additionnellement la teneur en eau, en graisse et en sel, le $\mathrm{pH}$, le pouvoir tampon et le degré de dégradation de la paracaséine. La dégradation était étudiée à la base des déterminations suivantes : azote précipité par des ions de $\mathrm{Ca}^{++}$, d'après le procédé de Garnier [7], modifié par Poznanski et Rymaszewski [9], azote soluble à pH 4,6 d'après Sode-Mogensen, azote non protéique d'après Schober et al. [12], azote peptidique d'après Boulanger et al. [5], azote aminé d'après Sirks, cité par Stadhouder [14] et azote des groupes $\alpha$-aminés, par le procédé de Kainz, d'après Alexander et Block [1]. En outre, on a effectué la distribution électrophorétique des protéines de fromage, précipitées avec des ions de $\mathrm{Ca}^{++}$sur le gel d'amidon par la méthode de Wake et Baldwin [17] modifiée par Schmidt [11]. Des fractions de protéines de fromage, précipitées avec des ions de calcium, étaient séparées par chromatographie sur colonne de DEAEcellulose d'après Mercier et al. [8].

\section{RESULTATS ET DISCUSSION}

Le rendement en germes de la fermentation lactique, que nous avons obtenu, est en moyenne, pour les souches utilisées, 1-2.10 germes $/ \mathrm{ml}$. Ces résultats coïncident avec ceux de Vallès et Mocquot [18] qui cultivaient des bactéries thermophiles dans le même milieu pour obtenir des valeurs semblables. Le nombre de germes obtenu est un peu moins élevé que celui de Bergère [2-4] qui utilisait des milieux synthétiques pour y cultiver des bactéries mésophiles. Pourtant des frais moins élevés du milieu au lactosérum en ont fait préférer l'usage, malgré le rendement un peu moindre, pour la production de la biomasse des bactéries lactiques.

La biomasse centrifugée et congelée étant ajoutée, à côté du levain usuel, au grain de la $1^{\text {re }}$ série de fabrication, aucune différence significative n'était observée entre des fromages témoins et expérimentaux au cours du procédé technologique, ainsi qu'au niveau du $\mathrm{pH}$, du lactose et du pouvoir tampon (tab. 1). On a pourtant observé un degré de dégradation un peu plus élevé des pro- 
TABLEAU 1

Changements $\mathrm{du} \mathrm{pH}$, du lactose et du pouvoir tampon dans des fromages Edam frais et affinés

\begin{tabular}{|c|c|c|c|c|c|c|c|c|c|}
\hline \multirow[b]{2}{*}{$I^{e}$ série } & \multicolumn{3}{|c|}{$\mathrm{pH}$} & \multicolumn{3}{|c|}{$\begin{array}{l}\text { Lactose } \\
\text { en p. } 100\end{array}$} & \multicolumn{3}{|c|}{$\begin{array}{c}\text { Pouvoir tampon } \\
\text { en ml } \\
0,05 \mathrm{~N} \mathrm{NaOH}\end{array}$} \\
\hline & $\mathrm{K}_{1}$ & & $D_{1}$ & $\mathrm{~K}_{1}$ & & $\mathrm{D}_{1}$ & $\mathrm{~K}_{1}$ & & $\mathrm{D}_{1}$ \\
\hline Avant le pressage .. .. & 5,90 & & 5,80 & 0,540 & & 0,600 & 2,53 & & 2,88 \\
\hline Après le pressage ... ... & 5,70 & & 5,65 & - & & - & - & & - \\
\hline $\begin{array}{l}24 \mathrm{~h} \text { après la fabrication } \\
\text { Après salaison }(3 \mathrm{j} \text { après la }\end{array}$ & 5,60 & & 5,55 & 0,210 & & 0,260 & 2,45 & & 3,02 \\
\hline fabrication) $\ldots \ldots \ldots$. & 5,45 & & 5,40 & 0,000 & & 0,020 & 3,20 & & 2,42 \\
\hline Après 6 semaines d'affinage & 5,45 & & 5,45 & - & & - & 2,62 & & 2,16 \\
\hline Après 12 semaines d'affinage & 5,45 & & 5,50 & - & & - & 5,62 & & 5,60 \\
\hline $\mathrm{II}^{\mathrm{e}}$ série & $\mathrm{K}_{2}$ & & $\mathrm{D}_{2}$ & $\mathrm{~K}_{2}$ & & $\mathrm{D}_{2}$ & $\mathrm{~K}_{2}$ & & $\mathrm{D}_{2}$ \\
\hline Avant le pressage ..... & 5,60 & & 5,25 & 0,980 & & 0,540 & 0,79 & & 2,71 \\
\hline Après le pressage ... .. . & 5,40 & & 5,20 & - & & - & - & & - \\
\hline $\begin{array}{l}24 \mathrm{~h} \text { après la fabrication } \\
\text { Après salaison }(3 \mathrm{j} \text { après la }\end{array}$ & 5,35 & & 5,15 & 0,040 & & 0,020 & 3,12 & & 4,03 \\
\hline fabrication) ......... & 5,30 & & 5,15 & 0,000 & & 0,000 & 2,18 & & 2,36 \\
\hline Après 6 semaines d'affinage & 5,50 & & 5,45 & - & & - & 3,00 & & 3,72 \\
\hline Après 12 semaines d'affinage & 5,55 & & 5,50 & - & & - & 3,74 & & 4,30 \\
\hline III $^{\mathrm{e}}$ série & $\mathrm{K}_{3}$ & $\mathrm{D}_{3}$ & $\mathrm{D}_{4}$ & $\mathrm{~K}_{3}$ & $\mathrm{D}_{3}$ & $\mathrm{D}_{4}$ & $\mathrm{~K}_{3}$ & $\mathrm{D}_{3}$ & $\mathrm{D}_{4}$ \\
\hline Avant le pressage $\ldots \ldots$ & 5,20 & 5,05 & 5,25 & 1,220 & 1,250 & 1,250 & 2,84 & 3,28 & 2,51 \\
\hline Après le pressage ... ... & 5,15 & 5,00 & 5,20 & - & - & - & - & - & - \\
\hline $\begin{array}{l}24 \mathrm{~h} \text { après la fabrication } \\
\text { Après salaison }(3 \mathrm{j} \text { après la }\end{array}$ & 5,10 & 4,95 & 5,15 & 0,470 & 0,100 & 0,460 & 2,94 & 3,20 & 2,70 \\
\hline fabrication) $\ldots \begin{array}{lllllll} & \ldots & \ldots & \ldots\end{array}$ & 5,10 & 4,95 & 5,10 & 0,004 & 0,002 & 0,002 & 1,75 & 2,66 & 1,78 \\
\hline Après 6 semaines d'affinage & 5,30 & 5,20 & 5,35 & - & - & - & 4,62 & 5,23 & 4,79 \\
\hline Après 12 semaines d'affinage & 5,75 & 5,65 & 5,75 & - & - & - & 5,55 & 5,75 & 4,95 \\
\hline
\end{tabular}

TABLEAU 2

Teneur en eau, en graisse et en $\mathrm{NaCl}$ des fromages d'Edam après 12 semaines d'affinage

\begin{tabular}{c|c|c|c|c}
\hline $\begin{array}{c}\text { Série } \\
\text { de } \\
\text { fabrication }\end{array}$ & $\begin{array}{c}\text { Lot } \\
\text { de } \\
\text { fromage }\end{array}$ & $\begin{array}{c}\text { Eau } \\
\text { en } \\
\text { p. 100 }\end{array}$ & $\begin{array}{c}\text { Graisse } \\
\text { en E.S. } \\
\text { (p. 100) }\end{array}$ & $\begin{array}{c}\text { NaCl } \\
\text { en } \\
\text { p. 100 }\end{array}$ \\
\cline { 1 - 2 } I & $\mathrm{K}_{1}$ & 42,1 & & \\
& & 47,4 & 2,43 \\
II & $\mathrm{D}_{1}$ & 42,7 & 48,0 & 2,13 \\
& $\mathrm{~K}_{2}$ & 40,0 & 45,0 & 2,21 \\
& $\mathrm{D}_{2}$ & 40,0 & 45,0 & 2,19 \\
III & $\mathrm{K}_{3}$ & 40,5 & 45,1 & 2,59 \\
& $\mathrm{D}_{3}$ & 40,4 & 45,0 & 2,50 \\
& $\mathrm{D}_{4}$ & 40,5 & 45,2 & 2,60 \\
\hline
\end{tabular}




\section{TABLEAU 3}

Degré de dégradation de la paracaséine dans des fromages d'Edam après 6 et 12 semaines d'affinage

\begin{tabular}{|c|c|c|c|c|c|c|c|c|c|c|c|c|}
\hline \multirow{3}{*}{ 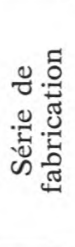 } & \multirow{3}{*}{ 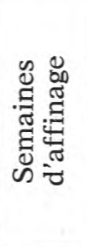 } & \multirow{3}{*}{ 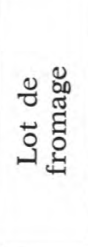 } & \multicolumn{10}{|c|}{ Produits de dégradation } \\
\hline & & & \multicolumn{5}{|c|}{ En p. 100 de $\mathrm{N}$ total } & \multicolumn{3}{|c|}{ En p. 100 de $\mathrm{N}$ soluble à $\mathrm{pH} 4,6$} & \multirow{2}{*}{$\begin{array}{c}\mathrm{N} \text { de } \\
\text { peptides } \\
\text { en p. } 100 \\
\text { de } \mathrm{N} \text { non } \\
\text { protéique }\end{array}$} & \multirow{2}{*}{$\begin{array}{c}\mathrm{N} \alpha-\mathrm{NH}_{2} \\
\text { en } \mathrm{mg} \mathrm{N} / \\
1 \mathrm{mg} \mathrm{N} \\
\text { non } \\
\text { protéique }\end{array}$} \\
\hline & & & $\begin{array}{c}\text { N prec. } \\
\text { avec } \\
\mathrm{Ca}++\end{array}$ & $\begin{array}{l}\text { N sol. } \\
\text { à } \\
\mathrm{pH} 4,6\end{array}$ & $\begin{array}{c}\mathrm{N} \\
\text { non } \\
\text { prot. }\end{array}$ & $\begin{array}{c}\mathrm{N} \\
\mathrm{de} \\
\text { pept. }\end{array}$ & $\begin{array}{c}\mathrm{N} \\
\text { d'acides } \\
\text { aminés }\end{array}$ & $\begin{array}{c}\mathrm{N} \\
\text { non } \\
\text { prot. }\end{array}$ & $\begin{array}{c}\mathrm{N} \\
\mathrm{de} \\
\text { pept. }\end{array}$ & $\begin{array}{c}\mathrm{N} \\
\text { d'acides } \\
\text { aminés }\end{array}$ & & \\
\hline I & 12 & $\begin{array}{l}\mathrm{K}_{1} \\
\mathrm{D}_{1}\end{array}$ & $\begin{array}{l}60,6 \\
57,9\end{array}$ & $\begin{array}{l}35,9 \\
36,7\end{array}$ & $\begin{array}{l}22,3 \\
25,9\end{array}$ & $\begin{array}{l}2,10 \\
2,65\end{array}$ & $\begin{array}{l}5,15 \\
5,38\end{array}$ & $\begin{array}{l}62,1 \\
70,5\end{array}$ & $\begin{array}{l}5,98 \\
7,24\end{array}$ & $\begin{array}{l}14,3 \\
14,6\end{array}$ & $\begin{array}{r}9,41 \\
10,26\end{array}$ & $\begin{array}{l}0,5131 \\
0,8461\end{array}$ \\
\hline II & $\begin{array}{r}6 \\
12\end{array}$ & $\begin{array}{l}\mathrm{K}_{2} \\
\mathrm{D}_{2} \\
\mathrm{~K}_{2} \\
\mathrm{D}_{2}\end{array}$ & $\begin{array}{l}77,0 \\
77,1 \\
68,5 \\
74,5\end{array}$ & $\begin{array}{l}39,6 \\
38,7 \\
40,9 \\
40,7\end{array}$ & $\begin{array}{r}8,7 \\
10,7 \\
13,1 \\
15,7\end{array}$ & $\begin{array}{l}0,86 \\
1,07 \\
0,90 \\
0,90\end{array}$ & $\begin{array}{l}3,81 \\
5,46 \\
5,76 \\
8,71\end{array}$ & $\begin{array}{l}21,9 \\
27,7 \\
31,9 \\
38,7\end{array}$ & $\begin{array}{l}2,17 \\
2,76 \\
2,22 \\
2,22\end{array}$ & $\begin{array}{r}9,8 \\
14,1 \\
13,9 \\
21,3\end{array}$ & $\begin{array}{l}9,87 \\
9,95 \\
6,95 \\
5,76\end{array}$ & $\begin{array}{l}0,4373 \\
0,6922 \\
0,3422 \\
0,8935\end{array}$ \\
\hline III & 12 & $\begin{array}{l}\mathrm{K}_{3} \\
\mathrm{D}_{3} \\
\mathrm{D}_{4} \\
\mathrm{~K}_{3} \\
\mathrm{D}_{3} \\
\mathrm{D}_{4}\end{array}$ & $\begin{array}{l}78,9 \\
73,9 \\
80,9 \\
64,6 \\
61,1 \\
61,1\end{array}$ & $\begin{array}{l}32,9 \\
31,2 \\
35,0 \\
35,9 \\
40,9 \\
36,7\end{array}$ & $\begin{array}{r}8,3 \\
10,9 \\
8,3 \\
16,0 \\
17,4 \\
16,1\end{array}$ & $\begin{array}{l}0,82 \\
0,86 \\
0,80 \\
1,85 \\
1,83 \\
1,74\end{array}$ & $\begin{array}{l}4,34 \\
5,18 \\
4,23 \\
5,38 \\
6,21 \\
5,32\end{array}$ & $\begin{array}{l}25,4 \\
34,8 \\
24,8 \\
44,6 \\
42,6 \\
44,0\end{array}$ & $\begin{array}{l}2,49 \\
2,80 \\
2,28 \\
5,15 \\
4,47 \\
4,78\end{array}$ & $\begin{array}{l}13,1 \\
16,5 \\
12,0 \\
14,9 \\
15,1 \\
14,6\end{array}$ & $\begin{array}{r}9,83 \\
8,05 \\
9,70 \\
11,65 \\
10,50 \\
10,87\end{array}$ & $\begin{array}{l}0,4825 \\
0,5627 \\
0,4972 \\
0,5748 \\
0,7238 \\
0,5523\end{array}$ \\
\hline
\end{tabular}


téines expérimentales et surtout en ce qui concerne le niveau de l'azote non protéique et des groupes accessibles $\alpha-\mathrm{NH}_{2}$ (tab. 3). L'addition de la biomasse à côté du levain usuel, semble intensifier la protéolyse, tout en considérant le fait que ce n'était qu'une certaine quantité de biomasse qui restait dans le grain du fromage, tandis que le reste était éliminé avec le lactosérum au cours du pressage préliminaire du fromage.

Des différences plus évidentes se faisaient observer, pourtant lorsque la biomasse était ajoutée directement au lait de fromagerie, au lieu du levain. En utilisant la biomasse centrifugée et congelée, ou bien non centrifugée et refroidie, une réduction évidente de la durée de la fabrication du fromage dans la cuve était obtenue. En même temps, on a constaté l'augmentation plus rapide de l'acidité, due à la fermentation plus rapide du lactose au cours du pressage et de la salaison des fromages (tabl. 1). Le séchage plus rapide du caillé et la fermentation plus rapide du lactose semblent être causés par l'activité plus élevée des germes bactériens qui avaient été introduits dans le lait avec la biomasse. Des résultats que nous avons obtenus sont en accord avec ceux de Rousseaux et al. [10], qui employaient additionnellement la biomasse des bactéries thermophiles pour la fabrication du fromage de Comté. Ils ont constaté, eux aussi, l'effet favorable de la biomasse sur le procédé du séchage du grain et la rapidité d'égouttage du fromage. Il est bien intéressant de comparer les changements du $\mathrm{pH}$ qui avaient lieu dans les fromages expérimentaux et témoins au cours de la fabrication et de l'affinage.

Bien que, avant le pressage, le $\mathrm{pH}$ des fromages expérimentaux fut déjà moins élevé que celui des fromages témoins, aucune différence de niveau du $\mathrm{pH}$ entre les fromages expérimentaux et témoins n'était constatée après 6 et 12 semaines d'affinage, malgré la capacité tampon plus élevée des fromages expérimentaux.

En comparant le degré de dégradation de la paracaséine dans des fromages témoins et ceux qui avaient été fabriqués avec la biomasse non centrifugée et refroidie de la $3^{\text {me }}$ série de fabrication, des différences paraissent moins évidentes que celles des fromages de la $2^{\text {me }}$ série. Dans la $3^{\text {me }}$ série, le degré de dégradation des protéines plus élevé était constaté dans des fromages qui avaient été additionnés de la biomasse centrifugée et congelée (tab. 3).

L'examen organoleptique démontrait toujours l'affinage plus avancé des fromages qui avaient été fabriqués avec la biomasse, congelée ou refroidie. Après 6 semaines d'affinage, les fromages expérimentaux se caractérisaient par leur arôme doux et typique, tandis qu'après 12 semaines, un léger arrière-goût de bouillon se faisait sentir, ce qui semble prouver que les fromages étaient un peu surmaturés. Par contre, les fromages témoins n'avaient de saveur typique qu'après 10-12 semaines. Pour renseignement, nous pouvons noter que les teneurs en eau, en graisse et en sel, des fromages 


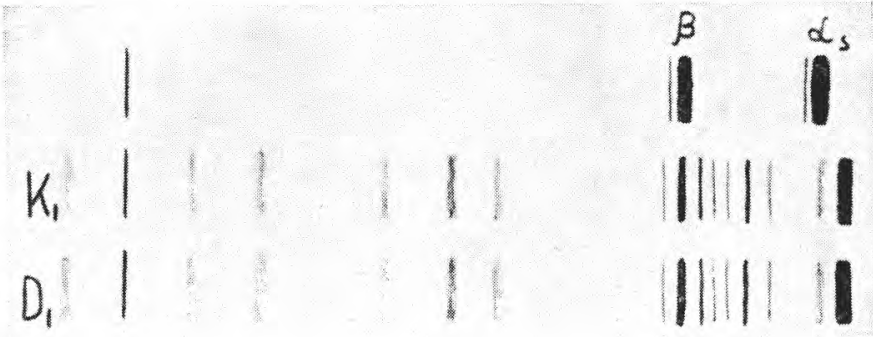

fig. 1

Distribution électrophorétique sur gel d'amidon des protéines de fromage précipitées avec des ions de $\mathrm{Ca}++$ de la $1^{\text {re }}$ série de fabrication.

$\mathrm{K}_{1}$ - fromage témoin ; $\mathrm{D}_{1}-$ fromage expérimental.

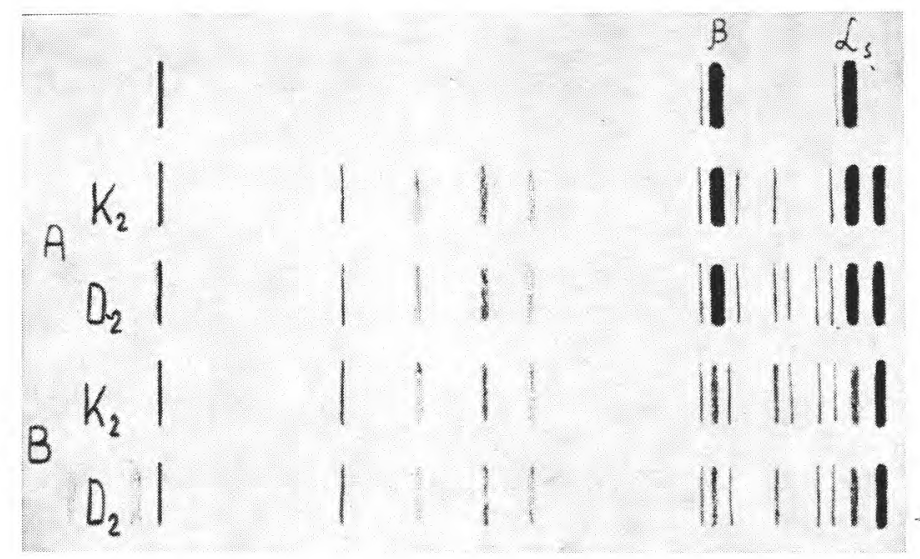

fig. 2

Distribution électrophorétique sur gel d'amidon des protéines de fromage précipitées avec des ions de $\mathrm{Ca}++$ de la $2^{\text {me }}$ série de fabrication.

A - après 6 semaines d'affinage.

B - après 12 semaines d'affinage.

$\mathrm{K}_{2}-$ fromage témoin ; $\mathrm{D}_{2}-$ fromage epérimental. 


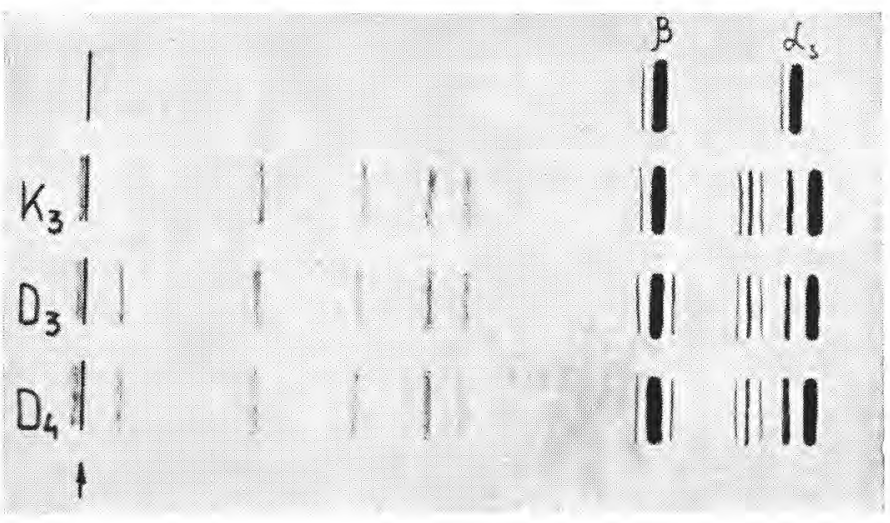

fig. 3

Distribution électrophorétique sur gel d'amidon des protéines de fromage précipitées avec des ions de $\mathrm{Ca}++$ de la $3^{\text {me }}$ série de fabrication après 6 semaines d'affinage.

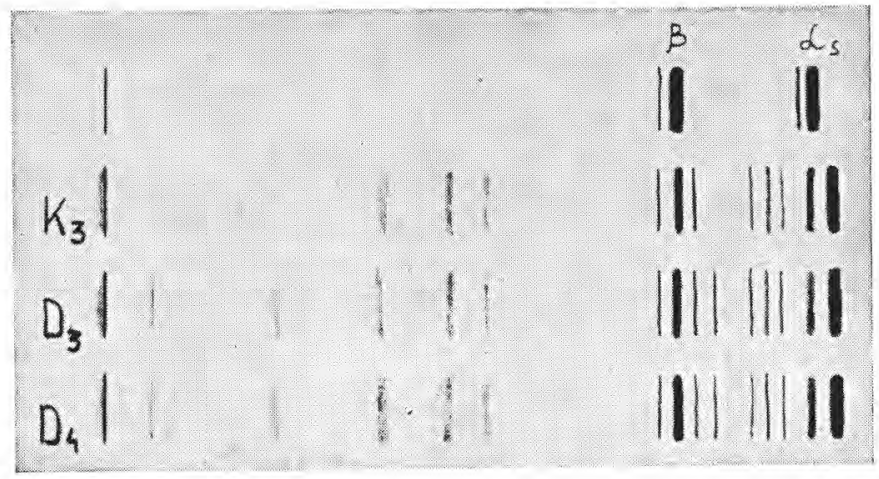

fig. 4

Distribution électrophorétique sur gel d'amidon des protéines de fromage précipitées avec des ions de $\mathrm{Ca}++$ de la $3^{\text {me }}$ série après 12 semaines d'affinage.

$\mathrm{K}_{3}$ - fromage témoin ; $\mathrm{D}_{3}, \mathrm{D}_{4}-$ fromages expérimentaux. 
témoins et expérimentaux, se ressemblaient beaucoup (tab. 2). Il semble donc peu probable que ces facteurs fissent différencier le cours de l'affinage des fromages. La distribution électrophorétique sur gel d'amidon des protéines de fromage précipitées avec des ions de $\mathrm{Ca}^{++}$n'a pas montré de différences essentielles entre les fromages expérimentaux et témoins. Ce n'est que dans les fromages expérimentaux de la $2^{\text {me }}$ série de fabrication (fig. 2) qu'on observait, après 12 semaines, deux fractions s'avançant vers la cathode, et dans les fromages expérimentaux de la $3^{\text {me }}$ série (fig. 3 et 4 ), une fraction avec une mobilité plus élevée que celle de la paracaséine. Des fractions migrant vers la cathode ont été pourtant trouvées aussi dans les fromages témoins et expérimentaux de la $1^{\text {re }}$ et la $3^{\text {me }}$ série de fabrication.

Des différences plus évidentes étaient constatées dans la distribution chromatographique sur DEAE-cellulose des protéines de fromage précipitées avec des ions de $\mathrm{Ca}^{++}$, qui sont bien les mêmes que l'on avait analysées par l'électrophorèse. Tandis que les protéines du fromage de la $3^{\text {me }}$ série de fabrication (fig. 5) se divisaient sur la colonne en sept fractions distinctes, la distribution des fractions principales $\left(\alpha_{s}\right.$ et $\beta$ ) ressemblait à celle de la caséine totale du lait, la distribution des protéines des fromages expérimentaux était tout à fait différente (fig 6 et 7). Dans les protéines des fromages

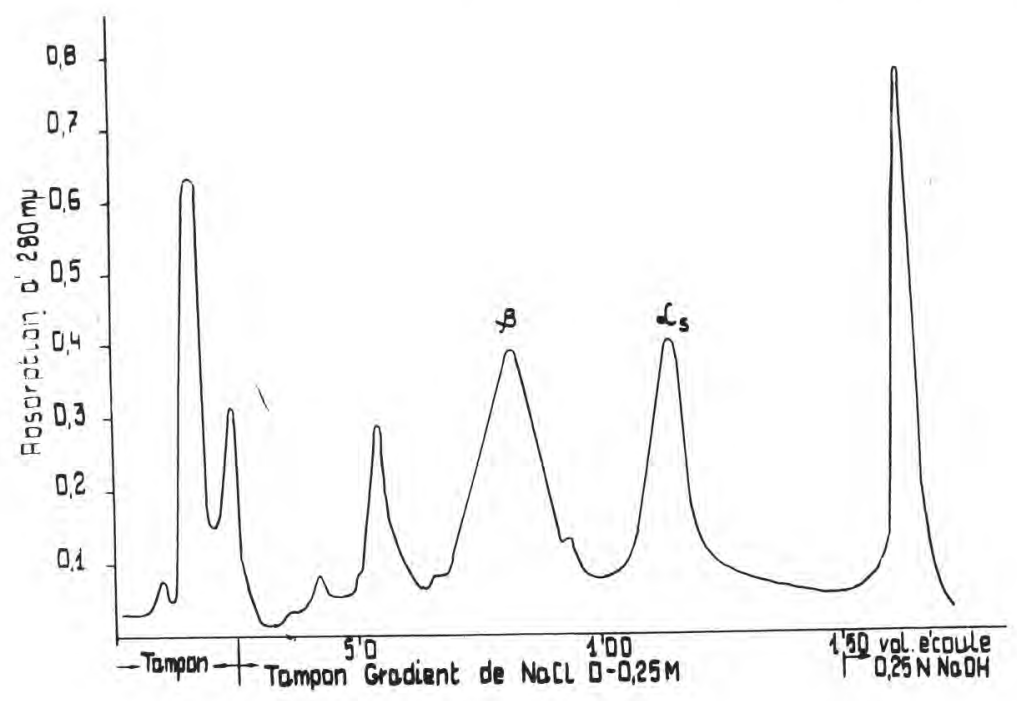

fig. 5

Chromatographie des protéines du fromage témoin $\left(\mathrm{K}_{3}\right.$-levain) précipitées avec des ions $\mathrm{Ca}++$ de la $3^{\text {me }}$ série de fabrication. Colonne DEAE-cellulose, diamètre $1 \mathrm{~cm}$, longueur $20 \mathrm{~cm}$.

Tampon : urée $3,3 \mathrm{M}$, imidasol $0,02 \mathrm{M}, \mathrm{HCl}, \mathrm{pH} 7$.

Vitesse de passage : $7 \mathrm{ml} / \mathrm{h}$, fraction $2 \mathrm{ml}$. 


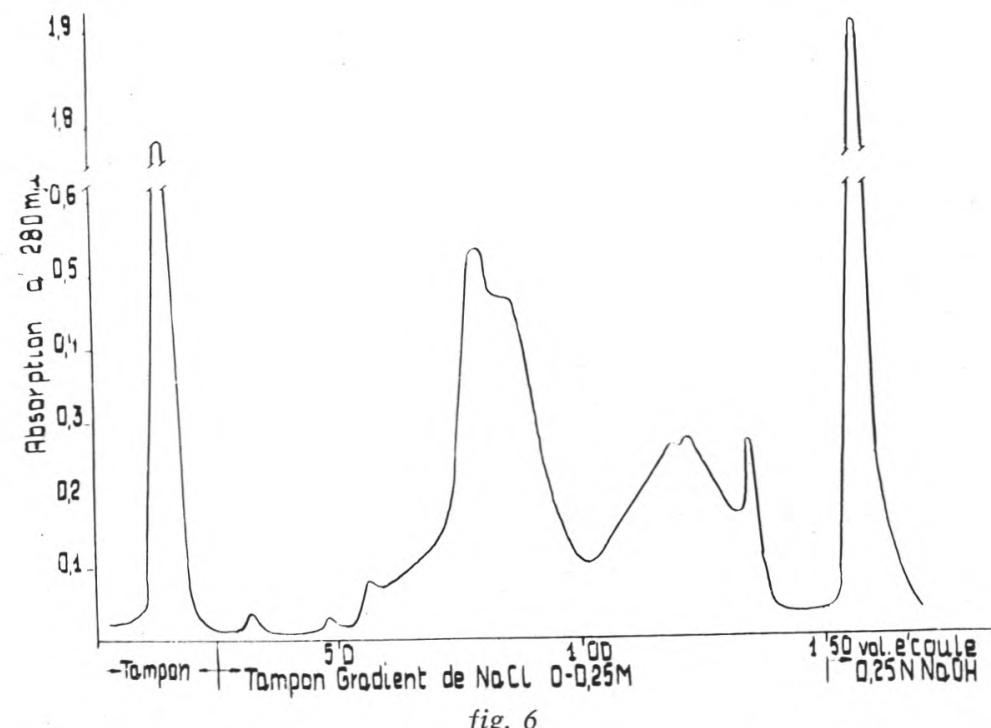

Chromatographie des protéines du fromage expérimental $\left(\mathrm{D}_{3}-\right.$ biomasse condensée, congelée) précipitées avec des ions de $\mathrm{Ca}++$, de la $3^{\text {me }}$ série de fabrication. Conditions de distribution v. fig. 5 .

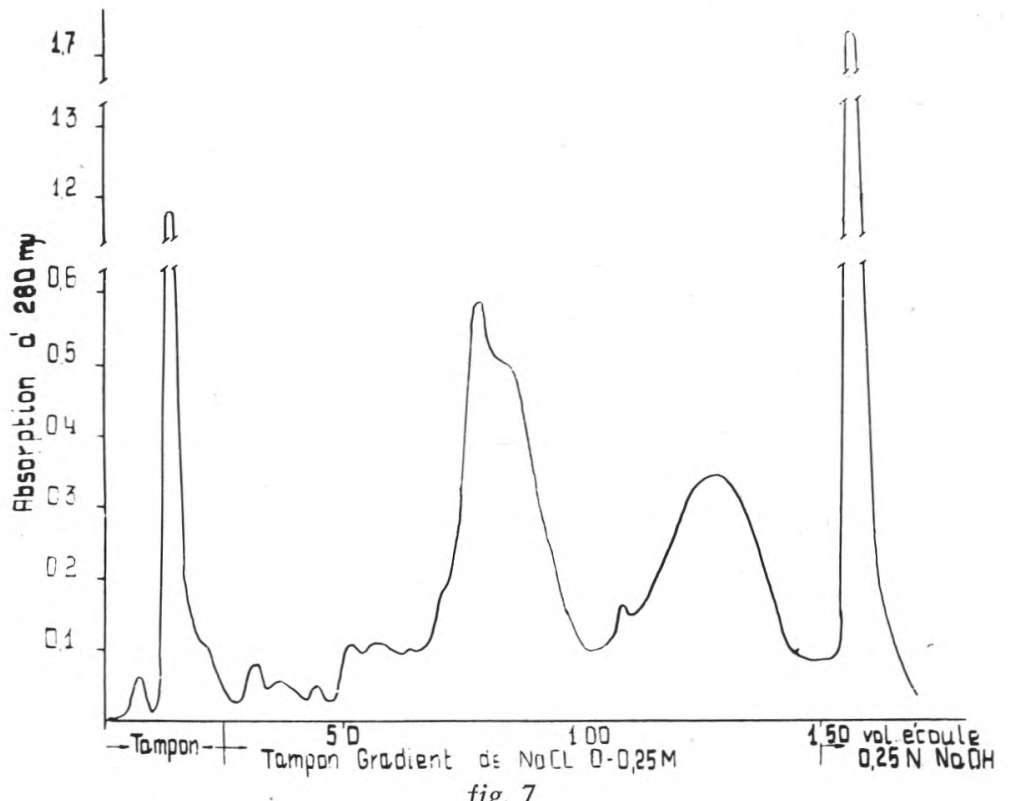

fig. 7

Chromatographie des protéines du fromage expérimental $\left(D_{4}-\right.$ biomasse fraîche) précipitées avec des ions de $\mathrm{Ca}++$ de la $3^{\text {me }}$ série de la fabrication. Conditions de distribution, v. fig. 5. 
$D_{3}$ et $D_{4}$, on a révélé une fraction beaucoup plus élevée qui se laissait éluer avec la solution tampon, avant que le gradient avec $\mathrm{NaCl}$ fut employé. On y a trouvé de même des fractions plus élevées des protéines qui exigeaient $0,25 \mathrm{~N} / \mathrm{NaOH}$ pour être éluées de la colonne. Des fractions principales $\alpha$ s et $\beta$ sont très déformées et la distribution en est beaucoup moins distincte que celle des protéines du fromage témoin. C'est d'autant plus intéressant que des différences en distribution chromatographique sont évidentes, bien que, après 12 semaines d'affinage, aucune différence évidente ne fut observée entre des fromages particuliers dans la teneur en azote précipité avec des ions de $\mathrm{Ca}^{++}$, celle en azote soluble, en azote non protéique, en azote peptidique et en azote aminé. Il paraît qu'au temps de l'affinage des fromages qui avaient été fabriqués avec la biomasse de bactéries, la structure de la paracaséine a subi des changements beaucoup plus avancés que ceux de la structure de la paracaséine des fromages qui étaient fabriqués avec le levain cultivé par le procédé classique. Ces différences sont d'accord avec les résultats de l'examen organoleptique.

L'acidification plus rapide de la pâte du fromage, la durée de la fabrication raccourcie et la vitesse plus élevée de l'affinage prouvent que la biomasse des bactéries de la fermentation lactique, centrifugée et congelée, ainsi que non centrifugée et refroidie, peut être employée avec succès dans la fabrication du fromage. Il semble que des recherches sur l'utilisation de la biomasse des bactéries de la fermentation lactique devraient être continuées, pour mettre au point des procédés bon marché et simples de culture, et, en même temps, une méthode efficace de la conservation. Une telle combinaison des souches doit être choisie qui garantirait la fabrication du fromage avec des caractéristiques de haute qualité.

\section{Résumé}

On a étudié l'utilité de la biomasse des bactéries de la fermentation lactique pour la fabrication du fromage d'Edam. L'expérimentation a démontré qu'en faisant usage de la biomasse des bactéries, centrifugées et congelées, ou bien refroidies sans centrifugation, des résultats satisfaisants étaient obtenus au cours de la fabrication et de l'affinage des fromages. L'acidification plus rapide de la pâte de fromage, la durée raccourcie de la fabrication et l'affinage plus rapide des fromages fabriqués avec la biomasse démontrent que la biomasse des bactéries lactiques l'emporte sur les levains cultivés par le procédé classique.

\section{S u m m a ry}

Studies were made on the suitability of the biomass of lactic fermentation bacteria for Edam cheese manufacture. The experiments showed that satisfactory results could be obtained by using the bacterial biomass, both centrifugated and frozen or cooled without centrifugation, in course of both manufacture and ripening of cheese body. Higher acidification rate of cheese body, reduced 
duration of manufacture and higher rate of ripening, as observed in cheeses made with the biomass indicate that the biomass of lactic fermentation bacteria may be prefered to the starters as cultivated by classic procedure.

\section{Bibliographie}

[1] Alexander (P.) and Block (R.) (1960). - Analytical Methods of Protein Chemistry. Pergamon Press, New-York, 2, 63.

[2] Bergère (J. L.) (1968). - Production massive de cellules de streptocoques lactiques. I - Méthodes générales d'étude et facteurs de la croissance de "Streptococcus lactis " souche $\mathrm{C}_{10}$. Le Lait, 47I-472, 1 .

[3] Bergère (J. L.) et Hermier (J.) (1968). - La production massive de cellules de streptocoques lactiques. II - Croissance de "Streptococcus lactis" en milieu à $\mathrm{pH}$ constant. Le Lait, 471-472, 13.

[4] Bergère (J. L.) (1968). - La production massive de cellules de streptocoques lactiques. III - Production de différentes souches en culture à $\mathrm{pH}$ constant. Le Lait, 473-474, 131.

[5] Boulanger (P.) (1949). - Bull. Soc. Chim. Biol., 31, 696.

[6] Czulak (J.), Conochie (J.), Sutherand (B. J.) and von Leeuven (H. J. M.) (1969). - Lactose, Lactic acid and mineral equilibre in Cheddar cheese manufacture. J. Dairy Res., 36, 93.

[7] Garnier (J.) (1962). - Etude cinétique de la protéolyse par la présure de caséine K. L'Université de Paris.

[8] Mercier (J. C.), Maubois (J. L.), Poznanski (S.) et Ribadeau-Dumas (B.) (1968). - Fractionnement préparatif des caséines de vache et de brebis par chromatographie sur DEAE-cellulose, en milieu urée et 2-mercaptoéthanol. Bull. Soc. Chim. Biol., 50, 34.

[9] Poznanski (S.) and Rymaszewski (J.) (1965). - Proteolysis during the ripening of Edam cheese with the participation of some bacteria strains. Part I, Milchwiss., 20, 14.

[10] Rousseaux (P.), Vassal (L.), Valles (E.), Auclair (J.) et Mocouot (G.) (1968). - Utilisation en fromagerie de suspensions concentrées et congelées de bactéries lactiques thermophiles. Le Lait, 475-476, 241.

[11] Schmidt (G.) (1964). - Starch gel electrophoresis of $\chi$-casein. Biochim. Biophys. Acta., 90, 411.

[12] Schober (K), Niclaus (W.) and Christ (W.) (1961). - Anwendung der "Finger Abdruck Methode " durch die Kennzeichnug von Kasesorten durch ihre proteolitischen Inhaltstoffe. Milchwiss., 16, 140.

[13] Sode-Mogensen (T.) (1948), - Determination of the degree of proteolytic decomposition in cheese with special reference to the formol titration. Meddelande 21 Franstatens Mejeriforsok. Alnarp. alkarp.

[14] Stadhouders (J.) (1960). - Neth. Milk Dairy Journal, 14, 82.

[15] Stadhouders (J.), Jensen (L. A.) and Hup (G.) (1968). - Preparation of starters and mass production of starter bacteria. Neth. Milk Dairy Journal, 21, 182.

[16] Swartling (P.) and Mattson (S.) (1953). - Determination of Lactose in cheese. XII Int. Dairy Congress, 3, 1224.

[17] WAKE (R.), BaLdWiN (R. L.) (1961). - Analysis of casein fractions by zone lectrophoresis in concentrated urea. Biochim. Biophys. Acta, 47, 225.

[18] Valles (E.) et Mocouot (G.) (1968). - Préparation de suspensions concentrées et congelées de bactéries lactiques thermophiles destinées à la fromagerie. Le Lait, 479-480, 631. 